\title{
Development of the BG-Malaria trap as an alternative to human-landing catches for the capture of Anopheles darlingi
}

\author{
Renata Antonaci Gama ${ }^{1,4}$, Ivoneide Maria da Silva², Martin Geier ${ }^{3}$ Álvaro Eduardo Eiras+ \\ 'Laboratório de Insetos e Vetores, Departamento de Microbiologia e Parasitologia, Centro de Biociências, Universidade Federal do Rio \\ Grande do Norte, Natal, RN, Brasil 'Laboratório de Parasitologia Médica, Instituto de Ciências Biológicas, Universidade Federal do Pará, \\ Belém, PA, Brasil ${ }^{3}$ Institut für Zoologie, University of Regensburg, Regensburg, Germany ${ }^{4}$ Laboratório de Ecologia Química de Insetos Vetores, \\ Departamento de Parasitologia, Instituto de Ciências Biológicas, Universidade Federal de Minas Gerais, Belo Horizonte, MG, Brasil
}

Although the human-landing catch (HLC) method is the most effective for collecting anthropophilic anophelines, it has been increasingly abandoned, primarily for ethical considerations. The objective of the present study was to develop a new trap for the collection of Anopheles darlingi. The initial trials were conducted using the BG-Sentinel trap as a standard for further trap development based on colour, airflow direction and illumination. The performance of the trap was then compared with those of the CDC, Fay-Prince, counterflow geometry trap (CFG) and HLC. All trials were conducted outdoors between 06:00 pm-08:00 pm. Female specimens of An. darlingi were dissected to determine their parity. A total of 8,334 anophelines were captured, of which 4,945 were identified as An. darlingi. The best trap configuration was an all-white version, with an upward airflow and no required light source. This configuration was subsequently named BG-Malaria (BGM). The BGM captured significantly more anophelines than any of the other traps tested and was similar to HLC with respect to the number and parity of anophelines. The $B G M$ trap can be used as an alternative to HLC for collecting anophelines.

Key words: Anopheles - monitoring - malaria - parity

The most common technique for the capture of anthropophilic anophelines is human-landing catches (HLC), which is highly efficient, primarily due to the mosquito-attracting odours emitted by the human body (Clements 1992). While this method may be the most effective means of collecting anophelines, it involves a number of ethical considerations and has been opposed increasingly by Brazilian authorities in recent years [The Federal Public Ministry (noticias.pgr.mpf.gov.br)].

A number of different types of traps have been developed or adapted to monitor anthropophilic anophelines, including the CDC and Shannon traps, the Odour-baited entry traps, Light-Bed net trap, Mosquito Magnet X (MMX)-trap, the Furvela, Ifakara and Mbita traps and the Mosquito Magnet (Charlwood et al. 1986, Costantini et al. 1993, Service 1993, Mathenge et al. 2002, Njiru et al. 2006, Qiu et al. 2007, Govella et al. 2009, Kweka \& Mahande 2009, Sikulu et al. 2009, Rubio-Palis et al. 2012). The basic trap principles are based on the use of illumination, natural or synthetic human odours and/or specific colours to attract the insects. However, none of the available traps have proven to be as sensitive or efficient as HLC, particularly with respect to the parity of the female specimens collected. In general, the traps collect a relatively large proportion of nulliparous females, whereas HLC attracts both parous and nulliparous fe-

doi: $10.1590 / 0074-0276108062013013$

+ Corresponding author: alvaro.eiras@gmail.com

Received 19 October 2012

Accepted 13 May 2013 males, thus providing a more reliable sample of the dynamics of the local female population. Reliable data on the parity and physiological age of females are extremely important for the evaluation of populations and the development of effective control measures by local health authorities (OMS 1975).

Whereas odours play a fundamental role in the attraction of Culicidae by humans, some studies have shown that visual characteristics, such as colour and contrast, are also important. Thus, Service (1993) has recommended that the physical characteristics of traps should also be considered carefully.

The BG-Sentinel trap (BGS) was developed at the University of Regensburg in Germany and attracts mosquitoes by simulating the odours and colouration of the host animal (Kroeckel et al. 2006). This device has proven to be relatively effective for the collection of African anophelines under semi-natural conditions (Schmied et al. 2008), as well as a number of other Culicidae in the field $(\mathrm{Kr}-$ oeckel et al. 2006, Maciel-de-Freitas et al. 2007, Williams et al. 2007). However, during preliminary field trials in 2005 in Porto Velho, in the Brazilian state of Rondônia (RO), the BGS was relatively ineffective for the collection of anthropophilic anophelines in general, and Anopheles darlingi in particular, of which only a single specimen was collected (unpublished observations). This species is of particular interest because it is the main vector of Plasmodium, which causes human malaria in Brazil.

Therefore, the aim of this work was to modify the BGS to improve its efficiency for the capture of anophelines in the Amazon Region, particularly An. darlingi. The performance of the new prototype, denominated BG-Malaria (BGM) (patent pending), was compared with other techniques for the capture of anophelines. 


\section{MATERIALS AND METHODS}

Study sites - The experiments were conducted during June and July in 2007 and 2008 in the rural communities of Mato Grosso (08 $\left.49^{\prime} 09^{\prime \prime} \mathrm{S} 63^{\circ} 56^{\prime} 15^{\prime \prime} \mathrm{W}\right)$ and São João (08 $44^{\prime} 40^{\prime \prime}$ 'S 6356'40"W), which are located in the municipality of Porto Velho, North Region of Brazil. The field trials were conducted in dense woods typical of the local tropical forest, which were characterised by an abundance of permanent mosquito breeding grounds, including rivers, creeks and lakes. Anophelines tend to be relatively abundant within the study area, where the predominant species is An. darlingi (Lourenço-de-Oliveira et al. 1989, Gama et al. 2009).

$B G S$ - The BGS (BioGents HmGb, Regensburg, Germany) consists of a cylindrical trap that is white in colour, $35 \mathrm{~cm}$ in diameter and $40 \mathrm{~cm}$ in height (Kröckel et al. 2006). A matte black collecting tube $(12 \mathrm{~cm}$ in diameter $\times 30 \mathrm{~cm}$ in length) containing a bag for the collection of insects is located in the centre of the trap (Supplementary data). An electric fan (12 V, $14 \mathrm{~cm}$ in diameter) powered by a $12 \mathrm{~V}$ battery $(7 \mathrm{~A})$ produces a downward flow of air, which draws in the insects that approach the collecting tube. This downward airflow also produces a subtle plume of odour when a chemical attractant is present. The traps were installed in the area surrounding a private residence (15 $\mathrm{m}$ from the building) and specimens were collected between 06:00 pm-08:00 pm. All collected Culicidae specimens were taken to the Entomology Laboratory at Central Laboratory, RO, where species were identified (Forattini 2002).

Carbon dioxide $\left(\mathrm{CO}_{2}\right)-\mathrm{CO}_{2}$ gas was obtained from dry ice stored in a 500 -mL Styrofoam bottle connected to a silicon tube with an average release rate of $25 \mathrm{~g} \mathrm{CO}_{2}$ per hour.

HLC - The Anopheles specimens were collected by eight experienced technicians with experience in the collection of anophelines. The technicians included five men (Caucasians, between 26-60 years old) and three women (mixed race, between 25-30 years old). The trial was also conducted in the back garden of a private residence, approximately $15 \mathrm{~m}$ from the building, over a 12-h period (06:00 pm-06:00 am).

Ethics - This study has been approved by the Ethical Committee of the Federal University of Minas Gerais (UFMG-COEP) (ETIC 0235/06) and all technicians signed an informed consent form, as recommended by the UFMG-COEP.

Experiment 1 - Evaluation of the position of the airflow in the BGS - The objective of this experiment was to assess the best position for the installation of the BGS for the collection of anophelines and the best direction of the flow of the air for the suction of the mosquitoes. Six different positions were tested. Three traps were installed at ground level, with the opening $40 \mathrm{~cm}$ above the ground and facing upwards, that is, in the normal position, sideways or downwards. The remaining three traps were installed with the opening $150 \mathrm{~cm}$ above the soil in the normal position, facing sideways or facing downwards.
The traps were baited with $\mathrm{CO}_{2}$ and the treatments were rotated among six positions during six nights following a Latin square design $(6 \times 6)$ with three repetitions (trapping effort of 18 samples for each position).

Experiment 2 - Evaluation of the role of illumination in the capture of anophelines - The effect of the addition of a light as a physical stimulus to the BGS trap baited with $\mathrm{CO}_{2}$ for the capture of anophelines was evaluated using the following treatments: (i) $\mathrm{CO}_{2}$ only, (ii) $\mathrm{CO}_{2}+$ white light (127 V, $5 \mathrm{~W}, 16 \mathrm{~mm} \times 41 \mathrm{~mm}$ ) and (iii) $\mathrm{CO}_{2}$ + ultraviolet (UV) light (127 V, $4 \mathrm{~W}, 16 \mathrm{~mm}$ x $149 \mathrm{~mm}$ ). The white and UV bulbs were fixed to the trap at a distance of approximately $15 \mathrm{~cm}$ from the opening using an iron bracket. A $12 \mathrm{~V} / 7 \mathrm{~A}$ battery was used to power the lamps. The treatments were rotated in three positions during three nights following a Latin square design ( $3 \mathrm{x}$ 3) with three repetitions (trapping effort of 9 samples for each treatment). In this and all subsequent experiments, the entrance to the trap faced downwards because this position was found to be the most effective configuration for the capture of anophelines in experiment 1.

Experiment 3 - Evaluation of contrast patterns (black-white) in the BGS - To identify the most effective contrast pattern for the capture of anophelines using the BGS, two experiments were conducted (Supplementary data): (i) different possible combinations of contrast between the main body and upper part of the trap and the collecting tube were evaluated: all parts of the trap were white in colour (WWW), all parts of the trap were black in colour (BBB), trap with white body, white upper part and black collecting tube (WWB), trap with white body, black upper part and white collecting tube (WBW), trap with white body, black upper part and black collecting tube (WBB), trap with black body, black upper part and white collecting tube (BBW), trap with black body, white upper part and white collecting tube (BWW) and trap with black body, white upper part and black collecting tube (BWB). The treatments were rotated in eight positions during eight nights following a Latin square design $(8 \times 8)$ with four repetitions (trapping effort of 32 samples for each colour). (ii) The prototypes presenting the best results in experiment, namely WWW, WBW and BWW, were compared with added contrast patterns (Supplementary data): white trap with horizontal black stripes (WHS), white trap with vertical black stripes (WVS), white trap with black checkering (WC), black trap with horizontal white stripes (BHS), black trap with vertical white stripes (BVS) and black trap with white checkering (BC). The treatments were rotated in nine positions during nine nights following a Latin square design $(9 \times 9)$ with two repetitions (trapping effort of 18 samples for each colour).

Experiment 4 - Comparison of the modified BGS (BGM) with other mosquito traps - The modified BGS with the alternative position and black-white contrast was denominated BGM (patent pending - MU88012921U2) for the remaining experiments. The BGM trap was compared with the Fay-Prince, counterflow geometry trap (CFG) and CDC traps, all of which were baited only with $\mathrm{CO}_{2}$ and powered by batteries. The treatments were 
rotated in four positions during four nights following a Latin square design $(4 \times 4)$ with three repetitions (trapping effort of 12 samples for each trap). The female An. darlingi collected in the traps were dissected following the procedure recommended by the OMS (1975) to determine their parity (presence of coiled tracheolar skeins).

Fay-Prince trap (Fay \& Prince 1970) - This trap was developed for the collection of Aedes aegypti and attracts primarily through the contrast of black and white colours. As the mosquitoes approach the trap, they are sucked into a collecting receptacle by a fan located in the upper part of the trap.

CFG (American Biophysics Corp, East Greenwich, RI, USA) - This device is designed to attract mosquitoes using synthetic attractants located internally (Kline 2002). The trap has two internal fans: one draws in the mosquitoes that approach the entrance, while the other liberates synthetic attractants. $\mathrm{CO}_{2}$ gas was used as attractant in this experiment.

CDC model 1012 (John W Hock Co, Gainesville, FL, USA) - This trap is normally used with a luminous attractant in the upper part of the device, just below which a fan draws in the insects and directs them into the collecting receptacle. The trap was used in the present study without a light source.

Experiment 5 - Comparison of the BG trap with HLC - To compare the performance of the BGM prototype with the most effective method known for the capture of anophelines - HLC - two 12-h samples (06:00 pm-06:00 am) were collected. The objective of this experiment was to evaluate the effectiveness of the trap during the night

\section{TABLE I}

Total and mean \pm standard error (SE) number of anophelines and Anopheles darlingi captured in BG-Sentinel traps with their openings in the normal, sideways and downward-facing positions set $40 \mathrm{~cm}$ and $150 \mathrm{~cm}$ above the ground in the settlement of Mato Grosso, state of Rondônia, Brazil

\begin{tabular}{lcccccc}
\hline & & \multicolumn{2}{c}{ Anopheles } & & \multicolumn{2}{c}{ An. darlingi } \\
\cline { 3 - 4 } \cline { 6 - 7 } Treatment & $\begin{array}{c}\text { Position } \\
(\mathrm{cm})\end{array}$ & $\begin{array}{c}\text { Total } \\
\text { (n) }\end{array}$ & Mean $\pm \mathrm{SE}$ & & $\begin{array}{c}\text { Total } \\
\text { (n) }\end{array}$ & Mean $\pm \mathrm{SE}$ \\
\hline Normal & 40 & 50 & $2.8 \pm 0.96^{b}$ & & 33 & $1.8 \pm 0.87^{a}$ \\
& 150 & 46 & $2.5 \pm 1.18^{b}$ & & 18 & $1.0 \pm 0.72^{a}$ \\
Sideways & 40 & 47 & $2.6 \pm 0.73^{b}$ & & 32 & $1.8 \pm 0.65^{a}$ \\
Downward & 40 & 69 & $3.8 \pm 1.17^{b}$ & & 42 & $1.3 \pm 0.77^{a}$ \\
& 150 & 132 & $7.3 \pm 3.15^{b}$ & & 105 & $5.8 \pm 3.17^{a}$ \\
\hline Total & - & 550 & $5.1 \pm 0.96$ & & 356 & $3.3 \pm 0.80$ \\
\hline
\end{tabular}

$a, b$ : the mean values in the same column followed by different letters are significantly different (Poisson, $\mathrm{p}<0.05$ ). Total number of anopheline specimens collected: unidentified anophelines + Anopheles benarrochi + An. darlingi. in comparison with HLC. The trap and HLC were used simultaneously at a distance of approximately $15 \mathrm{~m}$ from one another. The HLC were provided by six persons working in pairs; each pair was substituted every $2 \mathrm{~h}$.

The mosquitoes captured using both methods were collected each hour and stored in Styrofoam boxes for identification in the laboratory. As before, the female An. darlingi specimens were dissected to determine their parity, following OMS (1975).

Statistical analysis - All experiments used the Latin square design and the results were analysed using the Poisson model, which was run in R 2.6 for Windows. To compare the BGM trap with HLC, the data were transformed $(\sqrt{x}+1)$ and tested using Student's $t$ test and Pearson's correlation coefficient. When the data were not normally distributed, analysis was based on the MannWhitney $U$ test run in BioEstat 5.0 software.

\section{RESULTS}

Many of the anophelines captured during the present study could not be identified due to the poor condition of the specimens collected, including the loss of legs and wings during storage in the collecting bag of both types of BG traps, the original BGS and the modified BGM. However, previous studies in the same area recorded high densities of An. darlingi (Lourenço-deOliveira et al. 1989, Gama et al. 2009), suggesting that a large proportion of the unidentified specimens belonged to this species. In this case, the analysis of the data in all experiments was conducted for specimens identified as An. darlingi as well as for the whole set of anophelines collected (An. darlingi plus the damaged specimens).

Experiment 1 - Evaluation of the position of the airflow in the BGS - A total of 550 anophelines were captured, of which 356 (53.93\%) were An. darlingi and 192 were Anopheles spp. Only two specimens of Anopheles benarrochi were collected in the BGS traps in the normal $150 \mathrm{~cm}$ position. The mean number of An. darlingi specimens captured varied from $1.0 \pm 0.72$ (trap opening facing upwards at $150 \mathrm{~cm}$ ) to $7.0 \pm 3.27$ (trap opening facing downwards at $40 \mathrm{~cm}$ ), although there was no significant difference among treatments (Poisson, $\mathrm{p}>0.05$ ). Similar mean numbers of anophelines and An. darlingi were captured with the traps in the normal position and facing sideways. The largest number of anophelines was captured with the traps facing downwards at both heights $(40 \mathrm{~cm}$ and $150 \mathrm{~cm})$, although the traps set at 40 $\mathrm{cm}$ collected significantly more anophelines (Poisson, $\mathrm{p}$ $<0.01$ ) than the other traps (Table I).

In at least half of the sessions, no more than two anophelines were captured per night (Table II) and no more than eight specimens were captured in more than $80 \%$ of the trials. The exceptions were the two trials ( 40 $\mathrm{cm}$ and $150 \mathrm{~cm}$ ) in which the entrance faced downwards. In these cases, $33.3 \%$ and $27.8 \%$ of the trials captured more than eight anophelines, respectively, and these were the only sessions in which more than 26 specimens were collected in a given night. The traps at $40 \mathrm{~cm}$ in height with the entrance facing downwards were the most effective for the capture of Anopheles and consequently this configuration was adopted in all subsequent trials. 
TABLE II

Frequency of trials according to the number of anopheline specimens captured by BG-Sentinel traps set at different heights and orientations of the entrance in the settlement of Mato Grosso, state of Rondônia, Brazil, 2007

\begin{tabular}{|c|c|c|c|c|c|c|}
\hline & $\begin{array}{l}\text { Normal } \\
(40 \mathrm{~cm})\end{array}$ & $\begin{array}{l}\text { Normal } \\
(150 \mathrm{~cm})\end{array}$ & $\begin{array}{l}\text { Sideways } \\
(40 \mathrm{~cm})\end{array}$ & $\begin{array}{l}\text { Sideways } \\
(150 \mathrm{~cm})\end{array}$ & $\begin{array}{l}\text { Downwards } \\
\qquad(40 \mathrm{~cm})\end{array}$ & $\begin{array}{c}\text { Downwards } \\
(150 \mathrm{~cm})\end{array}$ \\
\hline Class & n $(\%)$ & n $(\%)$ & n $(\%)$ & $\mathrm{n}(\%)$ & n (\%) & $\mathrm{n}(\%)$ \\
\hline $0-2$ & $12(66.7)$ & $15(83.3)$ & $12(66.7)$ & $9(50)$ & $9(50)$ & $9(50)$ \\
\hline $3-5$ & $2(11.1)$ & $1(5.6)$ & $2(11.1)$ & $5(27.8)$ & $2(11.1)$ & $3(16.7)$ \\
\hline $6-8$ & $3(16.7)$ & $1(5.6)$ & $3(16.7)$ & $2(11.1)$ & $1(5.6)$ & $1(5.6)$ \\
\hline $9-11$ & $0(0)$ & $0(0)$ & $1(5.6)$ & $0(0)$ & $0(0)$ & $2(11.1)$ \\
\hline $12-14$ & $0(0)$ & $0(0)$ & - & $1(5.6)$ & $2(11.1)$ & $2(11.1)$ \\
\hline $15-17$ & $1(5.6)$ & $0(0)$ & - & $0(0)$ & $0(0)$ & $0(0)$ \\
\hline $18-20$ & - & $0(0)$ & - & $1(5.6)$ & $1(5.6)$ & $0(0)$ \\
\hline $21-23$ & - & $1(5.6)$ & - & - & $0(0)$ & $0(0)$ \\
\hline $24-26$ & - & - & - & - & $0(0)$ & $0(0)$ \\
\hline $27-42^{a}$ & - & - & - & - & $1(5.5)$ & $0(0)$ \\
\hline $43-58^{a}$ & - & - & - & - & $2(11.1)$ & $1(5.6)$ \\
\hline Total & 18 (100) & 18 (100) & 18 (100) & 18 (100) & $18(100)$ & 18 (100) \\
\hline
\end{tabular}

$a$ : the interval was increased here due to the reduced number of anophelines captured in the intermediate classes.

\section{TABLE III}

Total and mean \pm standard error (SE) number of anophelines and Anopheles darlingi specimens captured in the BG-Sentinel traps baited with carbon dioxide $\left(\mathrm{CO}_{2}\right)$

under different light conditions at the settlement of Mato Grosso, state of Rondônia, Brazil

\begin{tabular}{lcccccc}
\hline & \multicolumn{2}{c}{ Anopheles } & & \multicolumn{2}{c}{ An. darlingi } \\
\cline { 2 - 3 } Treatment & $\begin{array}{c}\text { Total } \\
\text { (n) }\end{array}$ & Mean $\pm \mathrm{SE}$ & & $\begin{array}{c}\text { Total } \\
\text { (n) }\end{array}$ & Mean $\pm \mathrm{SE}$ \\
\hline $\mathrm{CO}_{2}+$ white light & 38 & $6.3 \pm 3.18^{a}$ & & 30 & $5.0 \pm 3.23^{a}$ \\
$\mathrm{CO}_{2}+$ ultraviolet light & 56 & $9.3 \pm 2.99^{a}$ & & 28 & $4.6 \pm 1.38^{a}$ \\
$\mathrm{CO}_{2}$ & 144 & $24.0 \pm 7.67^{b}$ & 97 & $16.2 \pm 5.3^{b}$ \\
\hline Total & 238 & $25.0 \pm 3.33$ & 155 & $16.3 \pm 2.35$
\end{tabular}

$a, b$ : the mean values followed by different letters are significantly different (Poisson, $\mathrm{p}<0.05$ ). Total number of anopheline specimens collected: unidentified anophelines + An. darlingi.

Experiment 2 - Evaluation of the role of light source in anopheline capture - A total of 238 anophelines were captured, of which 155 (65.1\%) could be identified as $A n$. darlingi. The overall mean number of anophelines captured was $25.0 \pm 3.33$, ranging from $6.3 \pm 3.18\left(\mathrm{CO}_{2}+\right.$ white light) to $24.0 \pm 7.67$ ( $\mathrm{CO}_{2}$ only). The mean number of anophelines and An. darlingi collected was similar for the traps baited with $\mathrm{CO}_{2}$ and light, irrespective of the source of the light. However, the results clearly indicated that the use of a light source reduced the effectiveness of the traps significantly and the number of specimens captured decreased two-four-fold. The mean numbers of anophelines and An. darlingi captured by the traps baited only with $\mathrm{CO}_{2}$ were significantly higher (Poisson, $\mathrm{p}$ $<0.05$ ) than those collected in the other two treatments, i.e., $\mathrm{CO}_{2}+$ white light and $\mathrm{CO}_{2}+\mathrm{UV}$ light (Table III).

Experiment 3 - Evaluation of contrast patterns (black-white) in the BGS - During the first part of the colour contrast experiment, 2,996 anophelines were captured, of which 1,995 (66.6\%) were identified as An. darlingi (Table IV). Significantly higher capture rates were recorded for the WBW (mean $16.31 \pm 3.73$ specimens), BWW (15.06 \pm 4.41$)$ and WWW traps (14.71 \pm 5.15$)$, although these configurations were not significantly different from each other (Poisson, $\mathrm{p}>0.05$ ). When only the specimens identified as An. darlingi were considered, the WWW, WBW, WBB, BWW and BBW traps were statistically similar to one another (Table IV). The lowest capture rate was obtained with the BWB trap in which 188 anophelines were collected, followed by the WWB trap, which captured only 241 anophelines.

In the second colour contrast experiment, 1,013 anophelines were captured, of which $730(72 \%)$ were $A n$. darlingi (Table V). The most effective trap for both anophelines and An. darlingi was the all-white prototype (Poisson, $\mathrm{p}$ $<0.05)$ in which 205 anophelines were collected $(11.38 \pm$ 5.71), of which 165 were identified as An. darlingi (9.16 \pm 4.62). The BWW and WBW traps, which performed similarly to the WWW trap in the previous experiment, were the second and third most effective, respectively, in this experiment, although they were not significantly different from WWW (Table V). The least effective traps were black body with white checkering $(2.61 \pm 0.71)$. 
TABLE IV

Total and mean \pm standard error (SE) number of anophelines and Anopheles darlingi captured in BG-Sentinel traps at São João, state of Rondônia, Brazil, with different configurations of colouration

\begin{tabular}{lccccc}
\hline & \multicolumn{2}{c}{ Anopheles } & & \multicolumn{2}{c}{ An. darlingi } \\
\cline { 2 - 3 } \cline { 5 - 6 } Treatment & $\begin{array}{c}\text { Total } \\
\text { (n) }\end{array}$ & Mean $\pm \mathrm{SE}$ & & $\begin{array}{c}\text { Total } \\
\text { (n) }\end{array}$ & Mean $\pm \mathrm{SE}$ \\
\hline WWW & 471 & $14.71 \pm 5.15^{a}$ & & 274 & $8.56 \pm 3.32^{a}$ \\
WWB & 241 & $7.53 \pm 9.08^{b}$ & & 157 & $7.53 \pm 5.86^{b}$ \\
WBW & 522 & $16.31 \pm 3.73^{a}$ & & 389 & $12.15 \pm 3.05^{a}$ \\
WBB & 374 & $11.68 \pm 3.06^{b}$ & & 248 & $7.75 \pm 2.38^{a}$ \\
BWW & 482 & $15.06 \pm 4.41^{a}$ & 291 & $9.09 \pm 2.50^{a}$ \\
BWB & 188 & $5.87 \pm 1.2^{b}$ & & 127 & $3.96 \pm 0.92^{b}$ \\
BBW & 370 & $11.57 \pm 2.62^{b}$ & & 296 & $9.25 \pm 2.10^{a}$ \\
BBB & 348 & $10.87 \pm 2.93^{b}$ & 213 & $6.65 \pm 1.40^{b}$ \\
\hline Total & 2,996 & $11.70 \pm 1.18$ & 1,995 & $7.79 \pm 0.79$ \\
\hline
\end{tabular}

$a, b$ : means in the same column followed by different letters are significantly different (Poisson, $\mathrm{p}<0.05$ ). Total number of anopheline specimens collected: unidentified anophelines + An. darlingi. BBB: all black (Fig. 3H); BBW: black body, black top, white tube (Fig. 3G); BWB: black body, white top, black tube (Fig. 3F); BWW: black body, white top, white tube (Fig. 3E); WBB: white body, black top, black tube (Fig. 3D); WBW: white body, black top, white tube (Fig. 3C); WWB: white body, white top and black collecting tube (Fig. 3B); WWW: all white (Fig. 3A).

Experiment 4 - Comparison of the modified BGS (BGM) with other mosquito traps - The BGM traps collected 410 anophelines (mean $=34.2 \pm 14.2$ ), of which 166 were identified as An . darlingi $(13.8 \pm 3.7)$. The CFG trap collected only 32 anophelines $(2.67 \pm 1.36)$, approximately 11-fold fewer specimens than the BGM, whereas the CDC trap captured only 19 specimens $(1.58 \pm 0.71)$, approximately 20-fold fewer than the BGM (Table VI). The Fay-Prince trap performed only slightly better than the CFG trap, collecting 36 anophelines.

Overall, the performance of the BGM trap was far superior to that of the other traps for the capture of both anophelines in general (Poisson, $\mathrm{p}<0.001$ ) and An. darlingi in particular (Poisson, $\mathrm{p}<0.001$ ). The BGM trap was the only trap that preserved all specimens adequately for subsequent dissection to determine the parity of the females, whereas the CFG trap had the lowest proportion of intact insects. In all traps, a higher percentage of parous females than nulliparous specimens was collected, with the exception of the CDC trap in which nulliparous females predominated (Fig. 1). However, there was no significant difference in the proportions of females among traps (Mann-Whitney $U, \mathrm{p}>0.05$ ). The CFG trap had a high percentage of females for which it was not possible to define their physiological condition and it was the only device from which no engorged females were obtained (Fig. 1).

\section{TABLE V}

Total and mean \pm standard error (SE) number of anophelines and Anopheles darlingi captured in BG-Sentinel traps at São João, state of Rondônia, Brazil, with the following configurations of colouration

\begin{tabular}{lccccc}
\hline & \multicolumn{2}{c}{ Anopheles } & & \multicolumn{2}{c}{ An. darlingi } \\
\cline { 2 - 3 } \cline { 5 - 6 } Treatment & $\begin{array}{c}\text { Total } \\
\text { (n) }\end{array}$ & Mean \pm SE & & $\begin{array}{c}\text { Total } \\
\text { (n) }\end{array}$ & Mean \pm SE \\
\hline WWW & 205 & $11.38 \pm 5.71^{a}$ & & 165 & $9.16 \pm 4.62^{a}$ \\
WHS & 113 & $6.27 \pm 2.16^{b}$ & & 65 & $3.61 \pm 0.80^{b}$ \\
WVS & 70 & $3.88 \pm 0.89^{b}$ & & 45 & $2.50 \pm 0.61^{b}$ \\
WBW & 127 & $7.05 \pm 1.97^{b}$ & & 95 & $5.27 \pm 1.93^{b}$ \\
WC & 97 & $5.38 \pm 1.91^{b}$ & & 63 & $3.50 \pm 1.29^{b}$ \\
BWW & 156 & $8.66 \pm 3.03^{b}$ & & 117 & $6.50 \pm 2.84^{b}$ \\
BHS & 123 & $6.83 \pm 2.39^{b}$ & & 100 & $5.55 \pm 2.22^{b}$ \\
BVS & 75 & $4.16 \pm 1.01^{b}$ & & 47 & $2.61 \pm 0.61^{b}$ \\
BC & 47 & $2.61 \pm 0.71^{b}$ & & 33 & $1.83 \pm 0.67^{b}$ \\
\hline Total & 1,013 & $12.42 \pm 0.87$ & & 730 & $8.95 \pm 0.72$ \\
\hline
\end{tabular}

$a, b$ : means in the same column followed by different letters are significantly different (Poisson, $\mathrm{p}<0.05$ ). Total number of anopheline specimens collected: unidentified anophelines $+A n$. darlingi. BC: black body with white checkering (Fig. 4F); BHS: black body with white horizontal stripes (Fig. 4D); BVS: black body with white vertical stripes (Fig. 4E); BWW: black body, white top, white tube (Fig. 4I); WBW: white body, black top, white tube (Fig. 4H); WC: white body with black checkering (Fig. 4C); WHS: white body with black horizontal stripes (Fig. 4A); WVS: white body with black vertical stripes (Fig. 4B); WWW: all white (Fig. 4G).

Experiment 5 - Comparison of the BGM trap baited with $\mathrm{CO}_{2}$ and HLC mosquitoes collected - A total of 1,538 anophelines were collected by HLC, of which 1,189 (77\%) were $A n$. darlingi, with the remainder unidentified. The results for the BGM trap were very similar to those for HLC, with 1,505 anophelines captured. However, only $19 \%$ of the specimens from the BGM traps could be identified due to their damaged condition, although all were most likely An. darlingi (291). The mean number of $A n$. darlingi collected per hour by HLC was $33.02 \pm 5.8$, compared with $8.08 \pm 1.8$ by the BGM trap.

The difference in the number of specimens captured using the two methods was not significant (Student's $t=$ $0.74, \mathrm{p}>0.05$ ). The mean number of anophelines collected per hour was very similar for the two methods, with $42.7 \pm 8.1$ for HLC and $41.8 \pm 15.3$ for the BGM trap. There was also a highly significant correlation between the two methods in the hourly captures over the 12-h collection period (Pearson's $\mathrm{r}=0.83 ; \mathrm{p}<0.0001$ ).

Periodicity - Both methods (HLC and BGM traps) captured specimens throughout the night, between 06:00 pm-06:00 am (Fig. 2), although in both cases the number of anophelines collected was high during the first hours of the night (06:00 pm-07:00 pm) and decreased during the course of the night (mostly between 04:00 am-05:00 


\section{TABLE VI}

Total and mean \pm standard error (SE) number of anophelines and Anopheles darlingi captured in the BG-Sentinel, CDC, counterflow geometry trap (CFG) and Fay-Prince traps in São João, state of Rondônia, Brazil

\begin{tabular}{lcccc}
\hline & \multicolumn{2}{c}{ Anopheles } & \multicolumn{2}{c}{ An. darlingi } \\
\cline { 2 - 5 } Trap & $\begin{array}{c}\text { Total } \\
\text { (n) }\end{array}$ & Mean $\pm \mathrm{SE}$ & $\begin{array}{c}\text { Total } \\
\text { (n) }\end{array}$ & Mean $\pm \mathrm{SE}$ \\
\hline BG-Malaria & 410 & $34.2 \pm 14.2^{a}$ & 166 & $13.83 \pm 3.74^{a}$ \\
CDC & 19 & $1.58 \pm 0.71^{b}$ & 17 & $1.42 \pm 0.56^{b}$ \\
Fay-Prince & 36 & $3.0 \pm 1.33^{b}$ & 23 & $1.91 \pm 0.92^{b}$ \\
CFG & 32 & $2.67 \pm 1.36^{b}$ & 23 & $1.91 \pm 0.92^{b}$ \\
\hline
\end{tabular}

$a, b$ : means in the same column followed by different letters are significantly different (Poisson, $\mathrm{p}<0.05$ ).

am). HLC was most effective at 07:00 pm, when 291 specimens were collected, while the lowest number of mosquitoes (34) was collected at 04:00 am. The BGM trap was most effective at $06: 00 \mathrm{pm}$ (578 specimens collected) and least efficient (16 insects) at 05:00 am.

The trap was more efficient than HLC during the first hours of the night - 06:00 pm-08:00 pm - although HLC was more effective during most of the rest of the nocturnal period (Fig. 2). The two methods captured the same number of specimens at 07:00 pm, 08:00 pm and 12:00 am and were highly similar from 03:00 am onwards. There was a peak in capture by HLC at 07:00 pm. For the BGM trap, there was an abrupt decrease in the capture of anophelines after 06:00 pm, with the number of anophelines captured declining throughout the rest of the night, although the rate of decrease levelled off from 09:00 pm, after which it stabilised until the end of the sampling period.

Parity - All An. darlingi specimens collected during the captures (1,189 by HLC and 291 by the BGM trap)

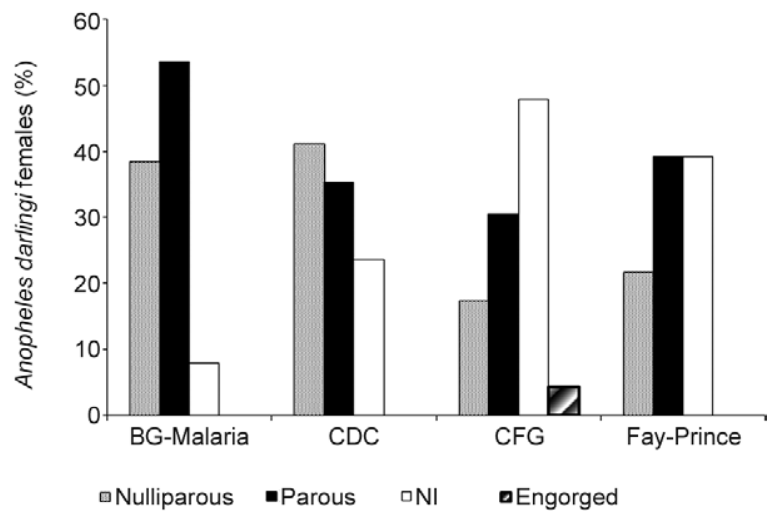

Fig. 1: percentage of dissected An. darlingi females collected in different traps at São João, state of Rondônia, Brazil, according to their parity. CFG: counterflow geometry trap; NI: physiological condition not identified. were dissected. Most of the females collected using HLC (50.7\%) were parous, whereas $36.6 \%$ were nulliparous (Fig. 3), although the difference between the two groups was not significant (Mann-Whitney $U, p>0.05$ ). Of the female An. darlingi captured in the BGM trap, $44.3 \%$ were parous and $49.1 \%$ were nulliparous. Again, no significant difference was found (Mann-Whitney $U, \mathrm{p}>0.05$ ).

While a significantly larger proportion of the insects captured in the BGM trap were damaged in comparison with those collected using HLC, only $6.5 \%$ of the females captured in the traps had damage to the abdomen that impeded the analysis of their parity, whereas $12 \%$ of those collected using HLC were damaged in this way (Fig. 3). Over the sampling period, the females captured using HLC were predominantly parous until 01:00 am, after which the majority were nulliparous. The proportions of parous and nulliparous females captured in the traps fluctuated considerably over the course of the night, with no clear pattern of variation.

\section{DISCUSSION}

The use of artificial traps to collect anophelines for the monitoring or control of populations has been considered for many years, but has invariably yielded relatively disappointing results. The most popular traps are those of the CDC type with a series of modifications, principally in relation to the airflow and type of illumination (Service 1993). In the present study, the BGS baited with $\mathrm{CO}_{2}$ and an upwards airflow was the most effective, as found by Wilton and Fay (1972) and Sexton et al. (1986), who demonstrated that a CDC trap with inverted airflow (upwards flowing) collected more anophelines than traps with the airflow in the normal position (downward flux).

The direction of the airflow appears to have a considerable influence on the efficiency of the traps. Njiru et al. (2006) confirmed that the MMX-trap is more efficient with an upward airflow. Service (1993) concluded that this system is more effective for the capture of mosquitoes because they attempt to escape by flying upwards when caught in an air current. Whereas airflow may be an important factor, the results of the present study indicate

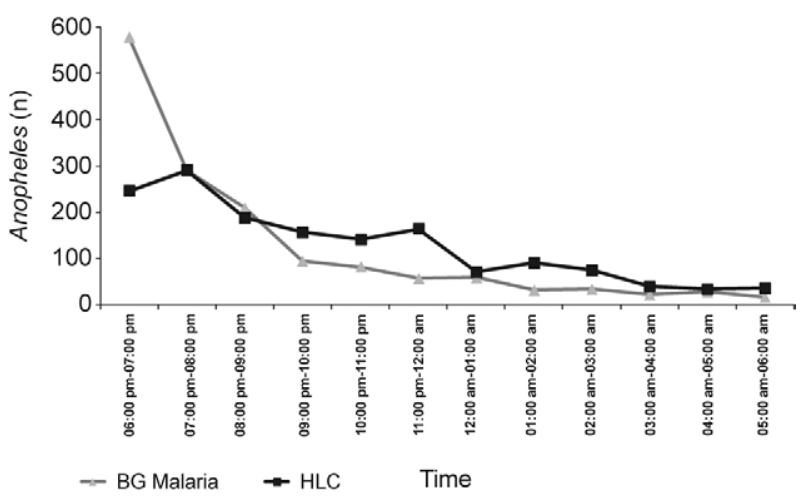

Fig. 2: total number of anophelines collected using human-landing catches (HLC) and the BG-Malaria trap over the 12-h sampling period at São João, state of Rondônia, Brazil. 
that other factors also influence this process, given that the CFG trap, which is similar to the MMX, captured only 36 anophelines, as opposed to 410 with the BGM trap.

In semi-natural trials, Schmied et al. (2008) collected more Anopheles gambiae in BGS with downward airflow than in MMX traps with upward flow. In addition to capturing larger numbers of anophelines, the BGS also displayed a higher capture frequency. Despite using a downward airflow, the BGS was installed below ground level, with the external portion $15 \mathrm{~cm}$ above the surface, which may have affected the effectiveness of the traps as this original configuration proved to be the least efficient in the present study. Together with the results of the present study, these findings indicate that the mosquitoes most likely fly close to the ground, which, in combination with the odours present on human feet, may account for the typically high biting rates of An. darlingi on the lower members of human subjects.

The role of illumination in the capture of anophelines is still unclear. In the laboratory, Das and Reuben (1978) demonstrated that UV light was effective for the capture of Anopheles stephensi, although less conclusive results have been obtained for more anthropophilic species (Service 1993). Wilton (1975) added $\mathrm{CO}_{2}$ to the CDC trap (with white and UV light) and recorded improvements in both cases, although the traps with UV light proved to be the most attractive. While illumination did not improve the performance of the traps tested in the present study, UV light was more effective than white light, even though the difference was not significant. The traps with UV light also captured large numbers of insects of other orders, such as Lepidoptera and Coleoptera, reflecting the trap's highly generalist potential.

Mosquitoes use olfaction and vision to locate their hosts over long distances (Clements 1992). Thus, it is extremely important for the trap to be coloured in a pattern that is attractive to the target species. The visual preferences of anophelines are still unclear; some studies have indicated a preference for black-coloured traps (Bidlingmayer \& Hem 1980), whereas the present study obtained the best results with white BGSs (WWW). This

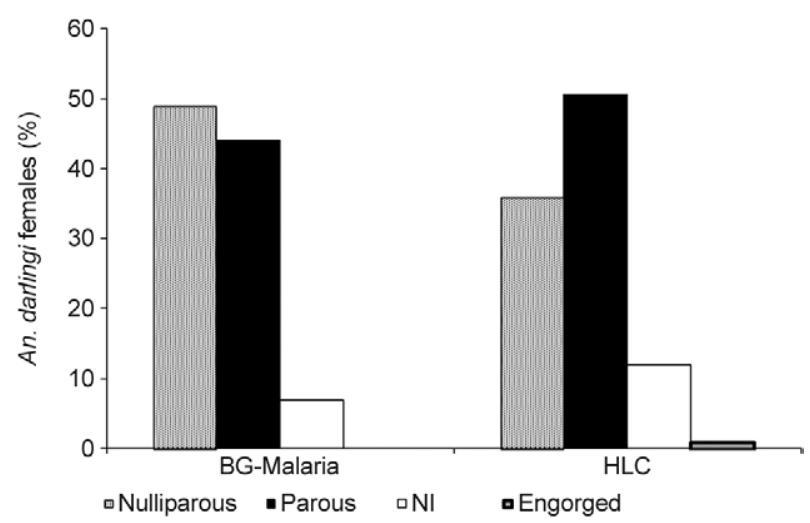

Fig. 3: percentage of dissected Anopheles darlingi females collected using human-landing catches (HLC) and the BG-Malaria trap at São João, state of Rondônia, Brazil, according to their parity. NI: physiological condition not identified. result reinforces the findings of Ko (1925), apud Brown (1966), who also recorded the preference of anophelines for white objects in the laboratory.

Some studies [e.g., Gibson (1970) apud Takken \& Knols (1999), Dennett et al. (2004), Hoel et al. (2011)] have shown that specific features of traps used for the capture of Culicidae, such as contrasts, particularly BC, are extremely important to guarantee the collection of the insects. However, such a preference was not observed in the present study, not only with regard to the different contrast patterns tested in the BGS (including stripes and checkering), but also for the ineffectiveness of the Fay-Prince trap, which uses black-white contrast as its principal attractant. This trap has been used extensively for the capture of Culicidae of the genus Aedes, for which it is relatively effective, particularly when baited with synthetic attractants (Silva et al. 2005). The striped and checkered BGSs used in the present study were as ineffective as the Fay-Prince traps.

While the use of HLC entails a number of potential problems, such as differences among collectors in attractiveness and ability as well the possibility of contracting diseases, it is still considered the most effective method for the capture of anthropophilic anophelines (Lounibos \& Conn 2000, Barros et al. 2007). In most comparative studies involving other approaches, HLC has proven to be the most efficient (Moreno et al. 2002, Mathenge et al. 2006, Hiwat et al. 2011).

Mboera (2005) proposed that, to be considered effective for the capture of anthropophilic anophelines, the performance of a trap must be compared with that of HLC and the trap must obtain equivalent results in terms of the number of specimens captured and the parity of the females. Parity is used by the Brazilian Health Ministry as an entomological parameter for the indirect evaluation of the transmission potential of a vector population and the effects of counter-measures such as the use of insecticides and mosquito nets.

While a number of studies have recorded relatively high capture rates using traps (Carnevale \& Pont 1973, Rubio-Palis 1996, Williams et al. 2006), the samples do not necessarily represent the anopheline population that feeds on humans, particularly in terms of the parity of the females, as parous females tend to be collected at much lower rates in traps than when HLC is used.

However, the BGM trap developed in the present study proved to be similar to HLC over a 12-h capture pe$\operatorname{riod}(06: 00 \mathrm{pm}-06: 00 \mathrm{am})$. This finding indicates that the BGM trap satisfies the conditions proposed by Mboera (2005), not only with respect to the number of specimens captured, but also their physiological condition, given that a similar proportion of parous females were captured by HLC. A similar result was obtained by Rubio-Palis et al. (1999) for An. darlingi in Venezuela. The CDC traps (with white and UV light) and HLC collected similar proportions of parous females, but in contrast to the BGM trap in the present study, HLC was much more effective than the CDC trap. However, the two methods tested in the present study displayed different peaks in their capture rates during the course of the night, with the traps collecting most of the specimens $(71.6 \%)$ during the first $3 \mathrm{~h}$ of the night 
(06:00 pm-08:00 pm), whereas HLC peaked at 07:00 pm. However, very similar total numbers of anophelines were collected (only 33 fewer in the traps), although the size of this difference increases if only the total number of identified specimens of An. darlingi is considered.

A total of 1,538 anophelines were collected by HLC, of which only $22.6 \%$ could not be identified, whereas the opposite trend was recorded for the traps, from which $80.7 \%$ of the specimens could not be identified. This result indicates the need for modifications to the suction mechanism and/or storage (collecting bag) of the insects inside the trap. The results for the BGM trap described in the present paper are promising for the use of this device to capture anophelines. This device was considerably more effective than the other commercial traps tested and performed almost as well as HLC, which is considered the most efficient method available. Further studies will be necessary for the modification and perfecting of the trap, particularly the need to reduce damage to the specimens during capture to ensure adequate species identification. It will also be important to substitute dry ice as a source of $\mathrm{CO}_{2}$ with synthetic attractants present in human odours.

\section{ACKNOWLEDGEMENTS}

To Dr Fátima dos Santos (LACEN-RO), for providing the infrastructure necessary for the present study, and to the municipal employees of Porto Velho and the LACEN-RO technicians, for their assistance with the collection of specimens in the field.

\section{REFERENCES}

Barros FSM, Arruda ME, Vasconcelos SD, Luitgards-Moura JF, Confalonieri U, Rosa-Freitas MG, Tsouris P, Lima-Camaratn H 2007. Parity and age composition for Anopheles darlingi Root (Diptera: Culicidae) of the northern Amazon Basin, Brazil. $J$ Vector Ecol 32: 54-68.

Bidlingmayer WJ, Hem DG 1980. The range of visual attraction and the effect of competitive visual attractants upon mosquito (Diptera: Culicidae) flight. Bull Entomol Res 70: 321-342.

Brown AWA 1966. The attraction of mosquitoes to host. Symposium. Insects and diseases. J Am Med Assoc 196: 159-162.

Carnevale P, Pont F 1973. Épidémiologié du paludisme humain en République Populaire du Congo. II - Utilisation des pièges lumineux "CDC" comme moyen d'échantilllonnage des populations anophèliennes. Cah ORSTOM sér Entomol Méd Parasitol 11: $263-270$

Charlwood JD, Paru R, Dagaro H 1986. A new ligth-bed net trap to sample anopheline vectors of malaria in Papua, New Guinea. J Vector Ecol 11: 281-283.

Clements NA 1992. The biology of mosquitoes: development, nutrition and reproduction, Vol. I, Chapman \& Hall, London, 532 pp.

Costantini C, Gibson G, Brady J, Merzagora L, Coluzzi M 1993. A new odour-baited trap to collect host-seeking mosquitoes. Parasitologia 35: 5-9.

Das PK, Reuben R 1978. Colour preference of An. stephensi Liston in the laboratory - a short note. Indian J Med Res 68: 752.

Dennett JA, Vessey NY, Parsons RE 2004. A comparison of seven traps used for collection of Aedes albopictus and Aedes aegypti originating from a large tire repository in Harris County (Houston), Texas. J Am Mosq Control Assoc 20: 342-349.
Fay RW, Prince W 1970. A modified visual trap for Aedes aegypti. Mosq News 30: 20-23.

Forattini OP 2002. Culicidologia médica: identificação, biologia e epidemiologia, Vol. II, EDUSP, São Paulo, 864 pp.

Gama RA, Santos RLC, Santos F, Silva IM, Resende MC, Eiras AE 2009. Periodicidade de captura de Anopheles darlingi Root (Diptera: Culicidae) em Porto Velho, RO. Neotrop Entomol 38: 677-682.

Govella NJ, Chaki PP, Geissbuler Y, Kannady K, Okumu F, Charlwood JD, Anderson RA, Killeen GF 2009. A new tend trap for sampling exophagic and endophagic members of the Anopheles gambiae complex. Malar J 8: 157-169.

Hiwat H, Andriessen R, de Rijk M, Koenraadt CJM, Takken W 2011. Carbon dioxide baited trap catches do not correlate with human landing collections of Anopheles aquasalis in Suriname. Mem Inst Oswaldo Cruz 106: 360-364.

Hoel DF, Obenauer PJ, Clark M, Smith R, Hughes TH, Larson RT, Diclaros JW, Allan SA 2011. Efficacy of ovitrap colors and patterns for attracting Aedes albopictus at suburban field sites in northcentral Florida. J Am Mosq Control Assoc 27: 245-251.

Kline DL 2002. Evaluation of various models of propane-powered mosquito traps. J Vector Ecol 27: 1-7.

Kröckel U, Rose A, Eiras AE, Geier M 2006. New tools for surveillance of adult yellow fever mosquitoes: comparison of trap catches with human landing rates in an urban environment. J Am Mosq Control Assoc 22: 229-238.

Kweka EJ, Mahande AM 2009. Comparative evaluation of four mosquitoes sampling methods in Rice irrigation schemes of lower Moshi, northern Tanzania. Malar J 8: 149-154.

Lounibos LP, Conn JE 2000. Malaria vector heterogeneity in South America. Am Entomol 46: 238-249.

Lourenço-de-Oliveira R, Guimarães AEG, Arlé M, da Silva TF, Castro MG, Motta MA, Deane LM 1989. Anopheline species, some of their habitats and relation to malaria in endemic areas of Rondônia state, Amazon Region of Brazil. Mem Inst Oswaldo Cruz 84: 501-514.

Maciel-de-Freitas R, Codeço CT, Lourenço-de-Oliveira R 2007. Daily survival rates and dispersal of Aedes aegypti females in Rio de Janeiro, Brazil. Am J Trop Med Hyg 4: 659-665.

Mathenge EM, Killeen GF, Oulo DO, Irungu LW, Ndegwa PN, Knols BGJ 2002. Development of an exposure-free bed net trap for sampling Afrotropical malaria vectors. Med Vet Entomol 16: 67-74.

Mathenge EM, Misiani GO, Oulo DO, Irungu LW, Ndegwa PN, Smith TA, Killeen GF, Knols BG 2006. Comparative performance of the Mbita trap, CDC light trap and the human landing catch in the sampling of Anopheles arabiensis, An. funestus and culicine species in a rice irrigation scheme in western Kenya. Malar J 4: 7-13.

Mboera LEG 2005. Sampling techniques for adult afrotropical malaria vectors and their reliability in the estimation of entomological inoculation rate. Tanzan Health Res Bull 7: 117-124.

Moreno J, Rubio-Palis Y, Pérez E, Sánchez V, Páez E 2002. Evaluación de tres métodos de captura de anofelinos en un área endémica de malaria del estado Bolívar, Venezuela. Entomotropica 17: $157-165$.

Njiru BN, Mukabana WR, Takken W, Knols BGJ 2006. Trapping of the malaria vector Anopheles gambiae with odour-baited MMXtraps in semi field conditions in western Kenya. Malar J 5: 39-47.

OMS - Organização Mundial da Saúde 1975. Manual de entomologia prática aplicada à malaria, Pt. II, OMS, $230 \mathrm{pp}$. 
Qiu YT, Ter BC, Spitzen J, Van Loon JJ, Jawara M, Milligan P, Galimard AM, Van Beek TA, Knols BG, Takken W 2007. Attractiveness of MM-X traps baited with human or sinthetic odor to mosquitoes (Diptera: Culicidae) in the Gâmbia. J Med Entomol 44: 970-983.

Rubio-Palis Y 1996. Evaluation of light traps combined with carbon dioxide and 1-octen-3-ol to collect anophelines in Venezuela. $J$ Am Mosq Control Assoc 12: 91-96.

Rubio-Palis Y, Guzmán H, Magris M 1999. Evaluación de la eficiencia de trampas de luz vs cebo humano para capturar Anopheles darlingi Root. Bol Dir Malariol Saneam Ambient 39: 30-32.

Rubio-Palis Y, Moreno JE, Sánchez V, Estrada Y, Anaya W, Bevilacqua M, Cárdenas L, Martínez A, Medina D 2012. Can Mosquito Magnet ${ }^{\mathbb{E}}$ substitute for human-landing catches to sample anopheline populations? Mem Inst Oswaldo Cruz 107: 546-549.

Schmied WH, Takken W, Killeen GF, Knols BGJ, Smallegange RC 2008. Evaluation of two conterflow traps for testing behaviormediated compounds for the malaria vector Anopheles gambiae s.s. under semi-field conditions in Tanzania. Malar J 7: 230-239.

Service MW 1993. Mosquito ecology-field sampling methods, 2nd ed., Chapman \& Hall, London, 988 pp.

Sexton JD, Hobbs JH, Jean YST, Jacques R 1986. Comparison of an experimental updraft ultraviolet light trap with the CDC miniature light and biting collections in sampling Anopheles albimanus in Haiti. J Am Mosq Control Assoc 2: 168-173.
Sikulu M, Govela NJ, Ogoma SB, Mpangile J, Kambi SH, Kannady K, Chaki PC, Mukabana WR, Killeen GF 2009. Comparative evaluation of the Ifakara Tend Trap-B, the standardized resting boxes and the human-landing catch for sampling malaria vectors and other mosquitoes in urban Dar es Salaam, Tanzania. Malar J 8: 197-206.

Silva IM, Eiras AE, Kline DL, Bernier UR 2005. Laboratory evaluation of mosquito traps baited with a synthetic human odor blend to capture Aedes aegypti. J Am Mosq Control Assoc 21: 229-233.

Takken W, Knols BG 1999. Odour-mediated behavior of afrotropical malaria mosquitoes. Annu Rev Entomol 44: 131-157.

Williams CR, Long JA, Russel C, Ritchie SA 2006. Field efficacy of the BG-Sentinel compared with CDC backpack aspirators and $\mathrm{CO}_{2}$ baited EVS traps for collection of adult Aedes aegypti in Cairns, Queensland, Australia. J Am Mosq Control Assoc 22: 296-300.

Williams CR, Long JA, Webb CE, Bitzhenner M, Geier M, Russel C, Ritchie SA 2007. Aedes aegypti population sampling using BG-Sentinel trap in north Queensland Austrália: statistical considerations for trap development and sampling strategy. $J$ Med Entomol 44: 345-350.

Wilton DP 1975. Mosquito collections in El Salvador with ultraviolet and CDC miniature light traps with and without dry ice. Mosq News 35: 522-525.

Wilton DP, Fay RW 1972. Air flow direction and velocity in light trap design. Entomol Exp Appl 15: 377-386. 


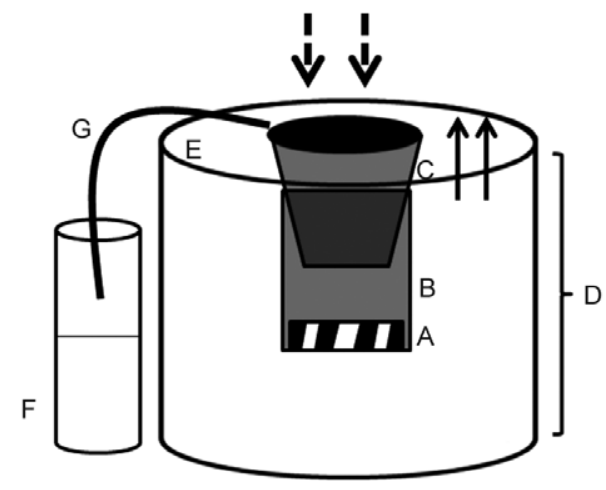

Diagram of the BG-Sentinel trap. A: electrical fan; B: collecting tube; C: collecting bag; D: main trap body; E: lid; F: Styrofoam bottle; G: silicon tube. The arrows indicate the direction of the airflow. Adapted from Kröckel et al. (2006).
A

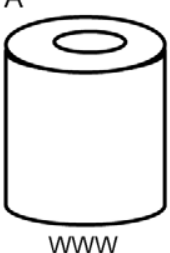

E

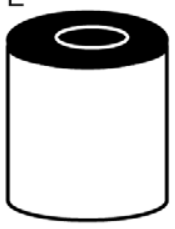

WBB
B

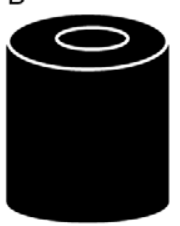

BBB

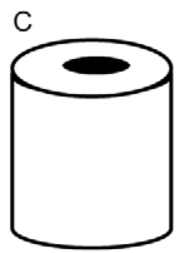

WWB

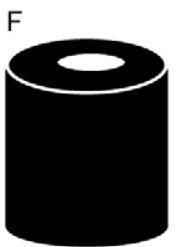

BBW
BWB

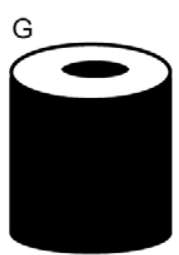

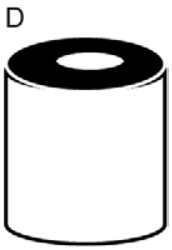

WBW

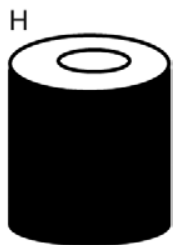

BWW

Different combinations of the colouration of the components of the BG-Sentinel trap tested in the present study: A: trap all white (WWW); B: all black (BBB); C: body and upper part white, collecting tube black (WWB); D: body white, upper part black, collecting tube white (WBW); E: body white, upper part and collecting tube black (WBB); F: body and upper part black, collecting tube white (BBW); G: body black, upper part white, collecting tube black (BWB); H: black body, upper part and tube white (BWW).

A

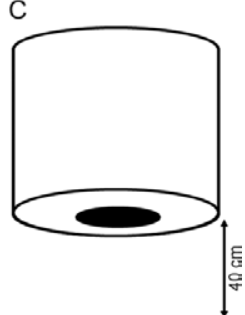

$\mathrm{F}$
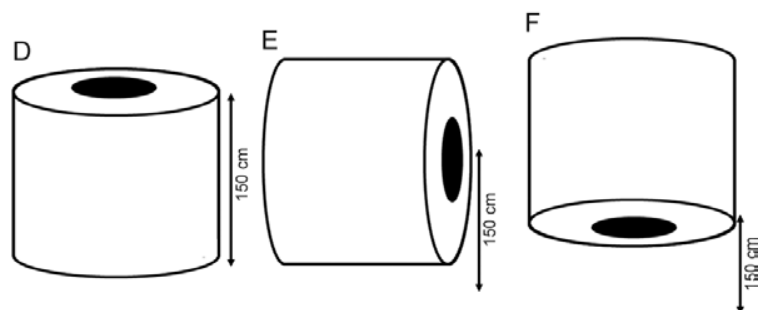

Diagram of the different configurations for the installation of the traps: A: normal at $40 \mathrm{~cm}$ high; B: sideways at $40 \mathrm{~cm}$; : downward at $40 \mathrm{~cm}$ high; D: normal at $150 \mathrm{~cm}$ high; E: sideways at $150 \mathrm{~cm}$ high; F: downward at $150 \mathrm{~cm}$ high.
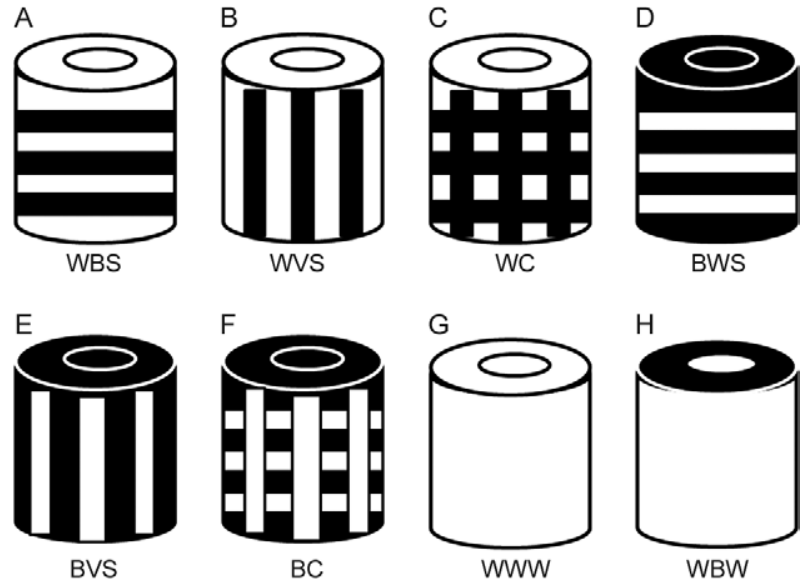

WWW
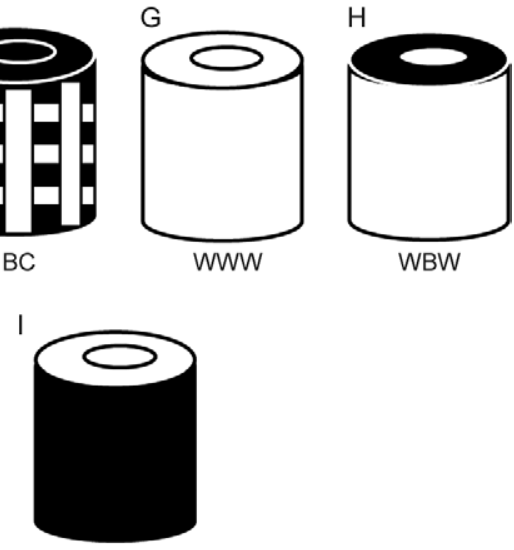

BWW

Different combinations of the colouration and contrast of the components of the BG-Malaria trap tested in the present study: A: white trap with horizontal black stripes (WHS); B: white trap with vertical black stripes (WVS); C: white trap with black checkering (WC); D: black trap with horizontal white stripes (BHS); E: black trap with vertical white stripes (BVS); F: black trap with white checkering (BC); G: trap all white (WWW); H: body white, upper part black, collecting tube white (WBW); I: black body, upper part and tube white (BWW). 